Check for updates

Cite this: Nanoscale Adv., 2019, 1, 2654

\section{Tin-zinc-oxide nanocomposites (SZO) as promising electron transport layers for efficient and stable perovskite solar cells $\dagger$}

\author{
Ahmed E. Shalan, $\star^{\star a}$ Ayat N. El-Shazly, $\star^{\text {ab }}$ Mohamed M. Rashad ${ }^{a}$ \\ and Nageh K. Allam (D) *b
}

\begin{abstract}
Tin-zinc-oxide nanocomposites (SZO) with various $\mathrm{Sn}: \mathrm{Zn}$ ratios were successfully fabricated and tested as electron transport layers (ETLs) in perovskite solar cells (PVSCs). The fabricated nanocomposites showed good crystallinity, good contact between layers, good electrical conductivity, and favorable light absorption, resulting in an enhancement in the net efficiency of $\mathrm{CH}_{3} \mathrm{NH}_{3} \mathrm{Pbl}_{3}$ (MAPI)-based perovskite solar cells. The device made of $\mathrm{SZO}-\mathrm{Sn}_{0.05}$ as an ETL showed a maximum power conversion efficiency (PCE) of $17.81 \%$ with a short-circuit current density $\left(J_{\mathrm{sc}}\right)$ of $23.59 \mathrm{~mA} \mathrm{~cm}{ }^{-2}$, an open-circuit voltage $\left(V_{\text {oc }}\right)$ of $1 \mathrm{~V}$, and a fill factor (FF) of 0.754 . However, the ETL containing lower $\mathrm{Sn}$ ratios showed PCEs of 12.02, 13.80 and $15.86 \%$ for pure $\mathrm{ZnO}, \mathrm{SZO}-\mathrm{Sn}_{0.2}$ and $\mathrm{SZO}-\mathrm{Sn}_{0.1}$, respectively. Meanwhile, the reproducibility of 30 fabricated devices proved the outstanding long-term stability of the cells based on SZO nanocomposites, retaining $\approx 85 \%$ of their PCE over $1200 \mathrm{~h}$ of operation. In addition, the incidentphoton-to-current efficiency (IPCE) exceeded $90 \%$ over the entire wavelength range from 400 to 800 $\mathrm{nm}$. The enhancement in the PCE of the fabricated PVSCs can be ascribed to the large surface area of the SZO nanoparticles, high charge extraction efficiency, and suppression of charge recombination provided by $\mathrm{SnO}_{x}$. The current results suggest that our synthesized tin-zinc-oxide nanocomposite is an effective electron transport layer for efficient and stable perovskite solar cells.
\end{abstract}

Received 25th March 2019

DOI: 10.1039/c9na00182d

rsc.li/nanoscale-advances

\section{Introduction}

Organic-inorganic hybrid halide perovskite solar cells (PVSCs) fabricated using $\mathrm{CH}_{3} \mathrm{NH}_{3} \mathrm{PbX}_{3}(\mathrm{X}=\mathrm{Cl}, \mathrm{Br}, \mathrm{I})$ have attracted great attention due to their low fabrication cost, achieving a certified power conversion efficiency (PCE) of 22.1\%. ${ }^{1}$ The high performance of PVSCs is related to the exceptional properties of the used perovskite material, being an excellent absorber and having a direct band gap, high absorption coefficient, and excellent

${ }^{a}$ Central Metallurgical Research and Development Institute (CMRDI), P. O. Box 87, 11422, Helwan, Cairo, Egypt. E-mail: a.shalan@cmrdi.sci.eg

${ }^{b}$ Energy Materials Laboratory, School of Sciences and Engineering, The American University in Cairo (AUC), 11835, New Cairo, Egypt. E-mail: nageh.allam@ aucegypt.edu

$\dagger$ Electronic supplementary information (ESI) available: Table summarizing the weight and atomic percentages of the produced nanocomposites obtained through EDX analysis; schematic diagram of LbL for the assembled PVSCs; optical transmittance and band gaps of pure $\mathrm{ZnO}$ and $\mathrm{Zn}_{1-x} \mathrm{Sn}_{x} \mathrm{O}(x=0.05,0.1$ and 0.2) nanocomposite films on FTO, respectively as well as XPS for MAPI on FTO. FTIR of SZO-Sn ${ }_{0.05}$. Hysteresis effect (reverse and forward scans) of $J-V$ curves for different ETLs. Correlation of the PCE with the roughness of different HTLs with respect to their conductivities. Furthermore, photovoltaic performance box charts of 30 PVSC devices assembled utilizing bare $\mathrm{ZnO}$, $\mathrm{SZO}-\mathrm{Sn}_{0.05}, \mathrm{SZO}-\mathrm{Sn}_{0.1}$ and $\mathrm{SZO}-\mathrm{Sn}_{0.2}$ as ETLs, and tables summarizing the corresponding photovoltaic parameters. See DOI: 10.1039/c9na00182d \$ Contributed equally to this work. carrier transport. ${ }^{2}$ However, the long-term stability under realistic operating conditions is a great challenge that needs to be addressed. ${ }^{3}$ A number of architectures have been proposed to assemble PVSCs. The widely used device assembly consists of an electron transport layer (ETL), a perovskite layer as the light harvesting material, and a hole transport layer (HTL). Controlling the quality of the perovskite/ETL interface is a key point to achieve long-term stability. ${ }^{4}$ Also, the dual functionality of the ETL, as either a hole blocking or an electron transfer layer, enhances the fill factor and the generated photocurrent by suppressing the recombination rate of charge carriers. ${ }^{5}$ To this end, various materials have been investigated as ETLs such as $\mathrm{TiO}_{2}, \mathrm{ZnO}$, $\mathrm{SnO}_{2}, \mathrm{Nb}_{2} \mathrm{O}$, and $\mathrm{WO}_{3}{ }^{6-10}$ Most PVSCs utilize $\mathrm{TiO}_{2}$ as a scaffold (ETL), which was reported to have a low electron mobility of 20 $\mathrm{cm}^{2} \mathrm{~V}^{-1} \mathrm{~s}^{-1}$ and requires high sintering temperature (usually above $\left.450{ }^{\circ} \mathrm{C}\right) . .^{11,12}$ Notably, ZnO has attracted considerable interest due to its good transparency, high electron mobility (200$300 \mathrm{~cm}^{2} \mathrm{~V}^{-1} \mathrm{~s}^{-1}$ ), and strong room temperature luminescence, and can be made crystalline under mild conditions. ${ }^{13,14}$ However, the efficiency of the PVSCs based on ZnO as an ETL is still relatively low due to the chemical instability of ZnO in acidic medium, which causes decomposition of methyl ammonium ions. ${ }^{15-18}$ On the other hand, $\mathrm{SnO}_{x}$ is a wide band gap semiconductor with a more positive conduction band (CB) edge, making it a better option as an ETL than $\mathrm{ZnO}$ and $\mathrm{TiO}_{2} \cdot{ }^{19} \mathrm{SnO}_{x}$ was shown to be 
more efficient in collecting electrons in electrochemical cells with high durability in an ambient environment. ${ }^{19}$ However, upon the use of $\mathrm{SnO}_{x}$, the assembled cells showed low PCE, which can be ascribed to the inherent low conduction band edge, resulting in a fast recombination process and low open-circuit voltage. ${ }^{20}$ Therefore, the combination of the two semiconductors ( $\mathrm{ZnO}$ and $\mathrm{SnO}_{x}$ ) into a composite material is expected to overcome the above mentioned limitations. The use of $\mathrm{SnO}_{x}-\mathrm{ZnO}$ (SZO) nanocomposites was shown to result in a higher photocatalytic activity than that of the individual $\mathrm{ZnO}$ and $\mathrm{SnO}_{x}$ counterparts, through reducing the electron-hole recombination rate. ${ }^{21-23}$ In addition, SZO nanocomposites were shown to be promising candidates as anode materials in rechargeable lithium ion batteries. ${ }^{24,25}$ Moreover, various SZO heterostructures have successfully been applied in both liquid and solid state dye-sensitized solar cells to enhance the photo-conversion efficiency of the fabricated devices. ${ }^{26-30}$ Similarly, the use of SZO as an ETL in PVSCs is an interesting subject to be investigated. ${ }^{31}$ To this end, and to the best of our knowledge, there is only one report in the literature on the use of a $\mathrm{ZnO} / \mathrm{SnO}_{2}$ nanocomposite. ${ }^{31}$ In that report, $\mathrm{SnO}_{x}$ was added to the ZnO structure as a photoanode in PVSCs with a PCE of $14 \% .^{31}$ However, this study was limited to only one composition with no variation in the $\mathrm{Zn}$ : Sn ratio, making it very hard to tell whether the improved performance was due to the cell assembly or the composition of the $\mathrm{ZnO} / \mathrm{SnO}_{2}$ nanocomposite, which necessitates further investigation. In this regard, the study of tin-zinc-oxide (SZO) nanocomposites with different Sn contents as an ETL for PVSCs is very essential to identify the best composition that enables the effective utilization of long-wavelength photons. Herein, we synthesized SZO nanocomposites with different Sn contents via a simple and cost-effective co-precipitation wet chemical method. The synthesized SZO nanocomposites were tested as ETLS in n-i-p PVSC devices. The synthesized nanocomposites and the assembled devices were extensively characterized and compared to the reports in the literature. ${ }^{31}$

\section{Experimental section}

\section{Chemicals and materials}

Zinc sulphate heptahydrate $\left(\mathrm{ZnSO}_{4} \cdot 7 \mathrm{H}_{2} \mathrm{O}\right)$ and stannous chloride dihydrate $\left(\mathrm{SnCl}_{2} \cdot 2 \mathrm{H}_{2} \mathrm{O}\right)$ were used as received from Dop Organic Chemical as a source of $\mathrm{Zn}^{2+}$ and $\mathrm{Sn}^{2+}$ ions, respectively, during the co-precipitation pathway. As a precipitating agent, ammonium hydrogen carbonate $\left(\mathrm{NH}_{4} \mathrm{HCO}_{3}\right)(99 \%$, Riedel-de Haën) was incorporated in the preparation reaction. The perovskite $\left(\mathrm{CH}_{3} \mathrm{NH}_{3} \mathrm{PbI}_{3}\right.$, MAPI) solution was prepared by adding $\mathrm{CH}_{3} \mathrm{NH}_{3} \mathrm{I}$, which was synthesized in the lab, to $\mathrm{PbI}_{2}(99 \%$, Aldrich) in an equimolar percentage in dry $N, N$-dimethyl formamide (DMF, Aldrich) as described elsewhere in our previous work. ${ }^{32-34}$ In addition, spiro-OMeTAD $\left(2,2^{\prime}, 7,7^{\prime}\right.$-tetrakis-( $N, N$-di-4-methoxyphenylamino)-9,90-spirobifluorene, as a HTL) was purchased from Lumtec.

\section{Synthesis of SZO nanocomposites}

Pure $\mathrm{ZnO}$, as a pristine sample, as well as tin-zinc-oxide (SZO) nanocomposites were synthesized by a co-precipitation method with the same recipe as mentioned in our previous published work. ${ }^{30}$ The recipe includes the adjustment of the $\mathrm{pH}$ to 11 for the solution mixture of zinc sulfate $\left(\mathrm{ZnSO}_{4}\right)$ and ammonium hydrogen carbonate $\left(\mathrm{NH}_{4} \mathrm{HCO}_{3}\right)$ solution $(2 \mathrm{M})$ for $\mathrm{ZnO}$ materials using diethyl amine as a stabilizer. Then, different amounts of $\mathrm{SnCl}_{2}$ were added to obtain SzO materials with different molar ratios $(0.05,0.1$ and $0.2 \%, \mathrm{w} / \mathrm{w})$. After that, the obtained sediment (either $\mathrm{ZnO}$ or $\mathrm{SZO}$ ) was filtered, cleaned many times with deionized water, and then dried at $60^{\circ} \mathrm{C}$ for 24 h. Ultimately, the desiccated precursors of the as-prepared SZO nanopowders at different molar ratios of $\mathrm{Sn}^{2+}$ ions $(0.05,0.1$, and $0.2 \%$ ) were annealed at $500{ }^{\circ} \mathrm{C}$ for $1 \mathrm{~h}$. The obtained powders were used to fabricate the desired photoanodes for solar cells after purification.

\section{Fabrication of electrodes and devices}

All ZnO and SZO based PVSC devices were fabricated on FTO substrates (TEC7, Hartford, USA), which were chemically etched to obtain the desired pattern followed by ultrasonic cleaning for $30 \mathrm{~min}$ with detergent, acetone, and isopropyl alcohol (IPA, 99.9\% Acros) and finally washed with deionized water for cleaning. The substrates were exposed to an ozone-UV lamp for $18 \mathrm{~min}$ to remove any organic leftover. After that, a layer of dense $\mathrm{TiO}_{2}$ was deposited on FTO substrates via spray pyrolysis to form a blocking layer. Then, films of bare $\mathrm{ZnO}$ or SZO (with different molar ratio contents of Sn: 0.05, 0.1, and 0.2\%) as ETL photoanodes were prepared by dispersion of the obtained powders in absolute ethanol $(1: 8 \mathrm{w} / \mathrm{v})$ and then filtered with a PVDF hydrophobic $0.45 \mathrm{~mm}$ filter and spin-coated at $5000 \mathrm{rpm}$ for $60 \mathrm{~s}$. To increase the hydrophilicity of the substrates, they were exposed again to an ozone-UV lamp for $18 \mathrm{~min}$. Subsequently, the perovskite films were prepared using one-step synthesis with the same sequence and steps according to the literature. ${ }^{35}$ As a hole transport layer (HTL), spiro-OMeTAD solution, doped with Li-TFSI in acetonitrile and 4-tert-butylpyridine, was dissolved in chlorobenzene, and then deposited via spin coating at $2000 \mathrm{rpm}$ for $30 \mathrm{s.}^{35}$ The final step was to evaporate aluminum (thickness $\sim 150 \mathrm{~nm}$ ) on the top of the devices through a shadow mask inside a thermal evaporation machine to complete the fabrication process; the active area of the (Al) electrodes in the fabricated device was $0.09 \mathrm{~cm}^{2}$ as shown in the schematic illustration in Fig. S1, in the ESI. $\dagger$

\section{Structural and morphological characterization}

XRD (Bruker axis D8 diffractometer) using $\mathrm{Cu}-\mathrm{K} \alpha(\lambda=1.5406)$ was used to elucidate the crystallinity and crystal structure of the synthesized materials. A FESEM (JEOL JSM-5410) and an AFM (Nanosurf C300 Controller Flex AFM, Switzerland) were used to identify the microstructure and surface roughness of the synthesized materials as well as for the cross-sectional imaging of the assembled solar cells, besides the EDX measurements of the obtained samples. The specific surface area $\left(S_{\mathrm{BET}}\right)$, pore size, pore volume and average pore size were realized on an ASAP 2020 (Micromeritics Instruments, USA) nitrogen adsorption apparatus. X-ray photoelectron spectroscopy (XPS) studies were pursued by using a Thermo Scientific K- 
ALPHA, XPS machine, England to identify the chemical composition of the prepared materials. The Fourier transform infrared (FTIR) absorption spectra were acquired using a JASCO 3600 spectrophotometer.

\section{Optical and photovoltaic measurements}

A UV vis-NIR scanning spectrophotometer (Jasco-V-570 Spectrophotometer, Japan) was used to measure the UV-vis absorption spectra of ETL materials as well as perovskites on different ETLs through a double beam machine using a reflectance accessory via filling the sample position with the desired sample deposited on an FTO substrate and the blank position filled with bare FTO. Moreover, PL spectra were monitored via a fluorescence spectrophotometer (Shimadzu RF-5301 PC, Japan). The PL measurements were performed with the help of an integrating sphere that created a light source with apparent uniform intensity over all positions of the measured samples. The $J-V$ measurements were recorded using a solar simulator. ${ }^{36}$ External quantum efficiency (EQE/IPCE) was measured using a measurement system (PVE 300, Bentham). Moreover, electrochemical impedance spectroscopy measurements (EIS) were pursued with a computer-controlled potentiostat (EG\&G, M273) equipped with a frequency response analyzer (EG\&G, M1025).

\section{Conductivity measurements}

An electrochemical analyzer (Potentiostat Model Parastat Princeton 4000) was used to detect the resistivity of the prepared materials. Resistivity was measured at several positions of the ETL surface from one direction and at the FTO part from the other direction. In order to get a precise comparison, a fixed distance between the ETL and FTO positions was applied. The reported results are the mean of almost 15 positions tested for each sample.

\section{Results and discussion}

To investigate the crystal structure of the synthesized SZO nanocomposites and the perovskite materials used in this study, their XRD spectra were recorded as depicted in Fig. 1a. The acquired results exhibit several diffraction peaks for the prepared materials, which are well matched with the diffraction peaks of the SnO-ZnO nanocomposite structure JCPDS (891397). ${ }^{37}$ No diffraction peaks related to $\mathrm{SnO}$ were detected indicating that the $\mathrm{Sn}^{2+}$ ions have substituted $\mathrm{Zn}^{2+}$ ions in the samples without changing its crystal structure. In addition, for $\mathrm{CH}_{3} \mathrm{NH}_{3} \mathrm{PbI}_{3}$ (MAPI) on SZO, the peaks marked with asterisks refer to the existence of the SZO nanocomposite in the tetragonal phase of the perovskite materials, which plainly appeared through the peaks at different $2 \theta$ positions with no impurities. ${ }^{42}$ Fig. 1b shows the surface morphology of the spin-coated perovskite film on $\mathrm{SZO}-\mathrm{Sn}_{0.05}$ with grain sizes ranging from 500 $\mathrm{nm}$ to $800 \mathrm{~nm}$, indicating the good crystallinity of the perovskite materials. ${ }^{36}$ Moreover, the AFM imaging of the perovskite film on SZO confirms the homogeneity and the large grain boundaries of the obtained film with a root-mean-square roughness $\left(R_{\mathrm{rms}}\right)$ of $52.9 \mathrm{~nm}$ as shown in Fig. 1c.

Fig. 2a-d show the FESEM and elemental mapping images of bare $\mathrm{ZnO}$ and SZO layers with different $\mathrm{Sn}: \mathrm{Zn}$ molar ratio compositions. The images reveal the formation of spherical nanoparticles with sizes in the range of $15-30 \mathrm{~nm}$ which are agglomerated in the form of a panicle-like morphology. While substituting $\mathrm{Zn}$ with $\mathrm{Sn}$ resulted in no change in the overall morphology, the particle size of the nanocomposites was slightly decreased. This decrease in the particle size should increase the (a)

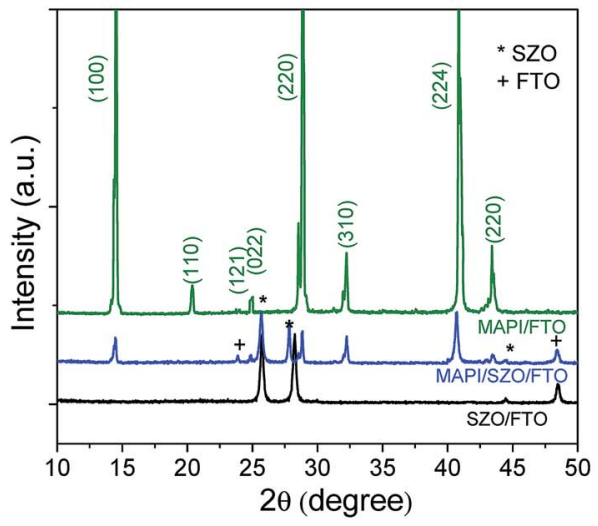

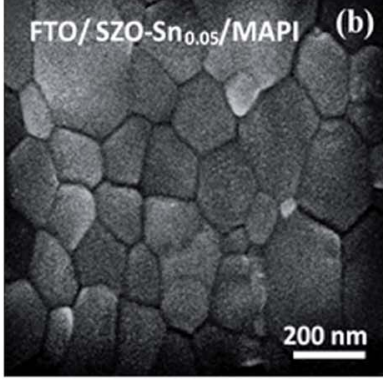

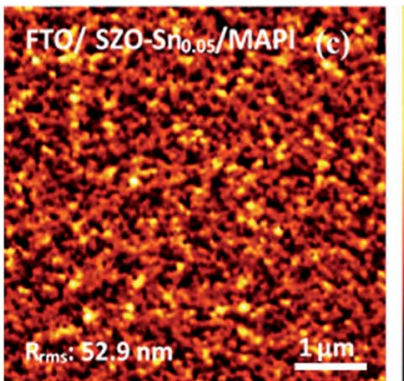

Fig. 1 (a) XRD of $\mathrm{SZO}-\mathrm{Sn}_{0.05}$ on FTO (black line), $\mathrm{FTO} / \mathrm{SZO}-\mathrm{Sn}_{0.05} / \mathrm{CH}_{3} \mathrm{NH}_{3} \mathrm{Pbl}$ (blue line), and $\mathrm{CH}_{3} \mathrm{NH}_{3} \mathrm{Pbl}$ ( on FTO (green line). The asterisks and the crosses refer to the planes of the SZO composite and FTO, respectively, (b) FESEM top-view image, and (c) AFM image of FTO/SZO$\mathrm{Sn}_{0.05} / \mathrm{MAPI}$. 

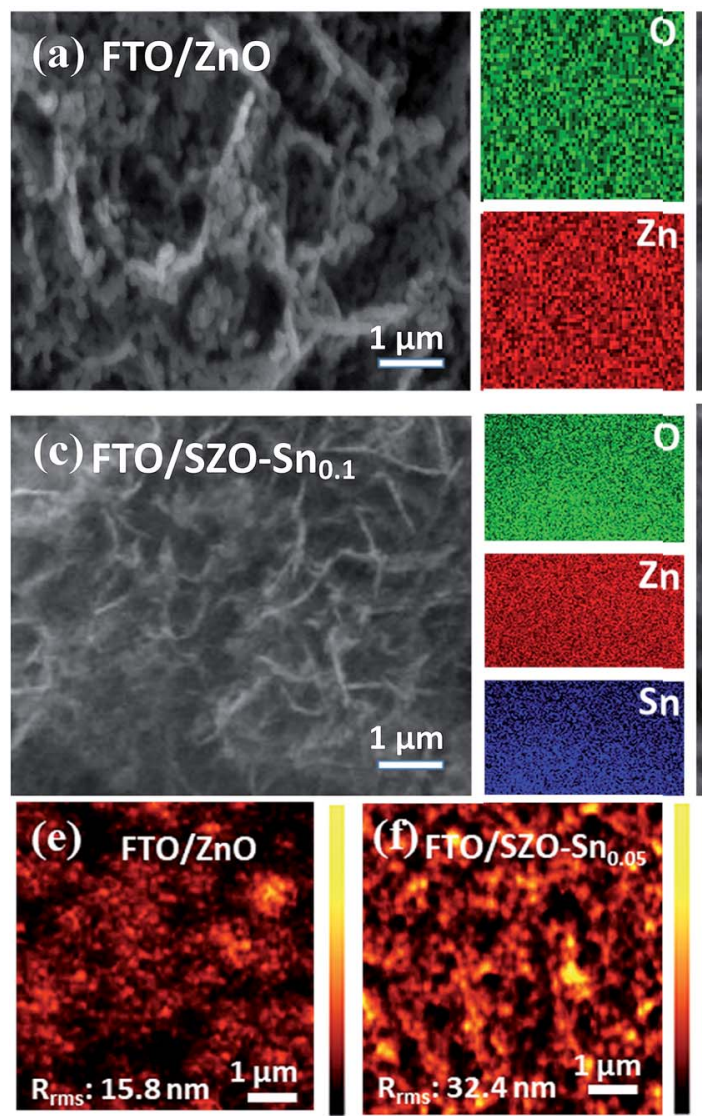
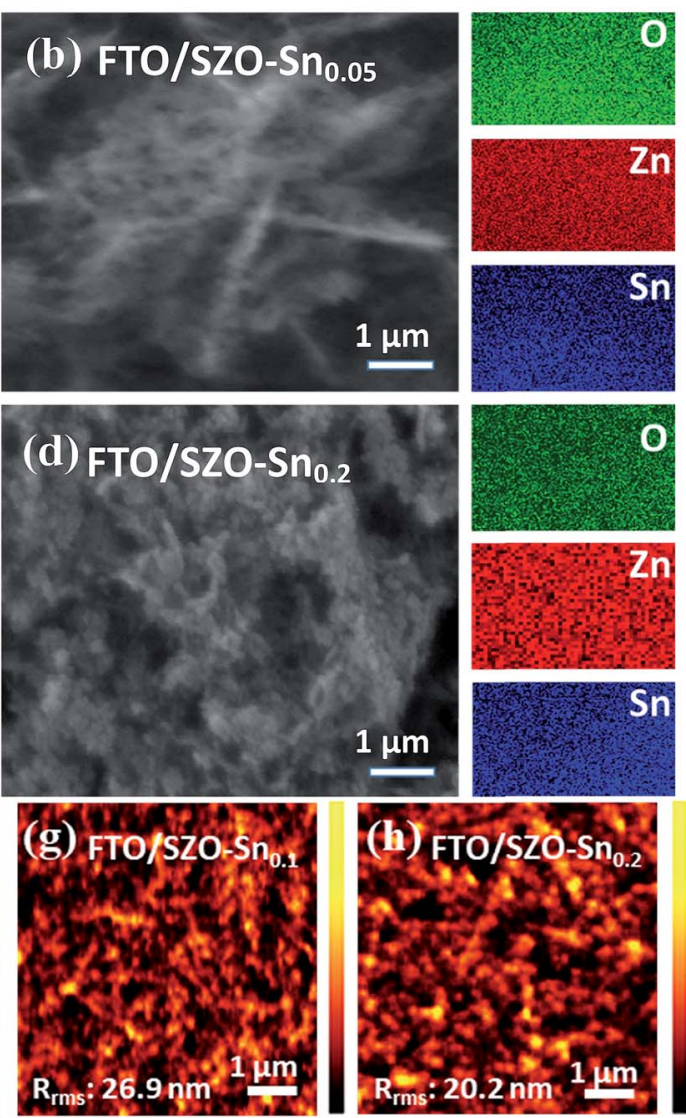

Fig. 2 FESEM and EDX mapping of (a) pristine $\mathrm{ZnO}$, (b) SZO-Sn $\mathrm{S}_{0.05}$, (c) SZO-Sn $\mathrm{n}_{0.1}$, and (d) SZO-Sn 0.2 . (e-h) AFM of the $\mathrm{ZnO}, \mathrm{SZO}-\mathrm{Sn} 0.05, \mathrm{SZO}-$ $\mathrm{Sn}_{0.1}$ and $\mathrm{SZO}-\mathrm{Sn}_{0.2}$ ETLs, on FTO substrates respectively.

surface area of the nanocomposites, which is favorable to enhance the efficiency of the assembled solar cells using these materials. Furthermore, the Sn content in the nanocomposites and its distribution are investigated using EDX mapping. The EDX results in the case of $\mathrm{ZnO}$ nanoparticles, Fig. 2a, indicate the presence of $\mathrm{Zn}$ and $\mathrm{O}$ elements and their homogeneous distribution. Moreover, the elemental mapping of $\mathrm{SZO}^{-\mathrm{Sn}_{0.05}}, \mathrm{SZO}^{-\mathrm{Sn}_{0.1}}$, and $\mathrm{SZO}-$ $\mathrm{Sn}_{0.2}$, respectively, demonstrates that the weight percent of $\mathrm{O}$ (green) varied from $=15.1$ to $26.1 \mathrm{wt} \%, \mathrm{Zn}$ (red) varied from 84.8 to $61.4 \mathrm{wt} \%$, and $\mathrm{Sn}$ (blue) varied from 0 to $20.6 \mathrm{wt} \%$. These results confirm the uniform distribution of Sn in the ZnO. The atomic and weight percentages of the elemental composition of the fabricated nanocomposites are listed in Table S1, in the ESI. Fig. 2e-h show the corresponding AFM images, confirming the homogeneity of the fabricated films with different root-meansquare roughness $\left(R_{\mathrm{rms}}\right)$ values that depend on the Sn content in the film, being $15.8 \mathrm{~nm}, 32.4,26.9$, and $20.2 \mathrm{~nm}$ for pure $\mathrm{ZnO}$, $\mathrm{SZO}-\mathrm{Sn}_{0.05}, \mathrm{SZO}-\mathrm{Sn}_{0.1}$, and $\mathrm{SZO}-\mathrm{Sn}_{0.2}$, respectively. The surface roughness of each SZO film was thus slightly more rugged than that of the pristine $\mathrm{ZnO}$ counterpart and increased with decreasing the Sn content, showing the highest value for SZO$\mathrm{Sn}_{0.05}$ samples. After deposition of different ETLs on the FTO substrate, nucleation of the crystals occurred and the grains replicated, which may cause the increase in the film roughness upon changing the Sn content in the SZO material structure. ${ }^{30,37-39}$
Fig. 3a shows a schematic representation of the assembled perovskite solar cell with a device layout of $\mathrm{FTO} / \mathrm{c}-\mathrm{TiO}_{2} / \mathrm{ETL} /$ $\mathrm{CH}_{3} \mathrm{NH}_{3} \mathrm{PbI}_{3}$ (MAPI)/spiro-OMeTAD/Al, and ETL is ZnO or SZO. The corresponding energy level diagram of the perovskite solar cell components depending on ZnO or SZO as the ETL is illustrated in Fig. 3b. The reported conduction band energy of $\mathrm{ZnO}$ is $4.2 \mathrm{eV}$ and $\mathrm{SnO}_{2}$ is $4.3 \mathrm{eV}$, which is very close to that of $\mathrm{SZO}(4.2$ $\mathrm{eV}) .^{30}$ Note that these values are lower than the value of the lowest occupied molecular orbital (LUMO) of $\mathrm{CH}_{3} \mathrm{NH}_{3} \mathrm{PbI}_{3}(3.9$ $\mathrm{eV}$ ), and thus electrons in the perovskite absorber material can easily transfer to the ETL, ensuring efficient dissociation of free charge carriers at the ETL/CH $\mathrm{CH}_{3} \mathrm{NH}_{3} \mathrm{PbI}_{3}$ interface. ${ }^{31,33}$ Fig. 3c shows a cross-sectional FESEM image of the assembled solar cell with the configuration of $\mathrm{FTO} / \mathrm{c}-\mathrm{TiO}_{2} / \mathrm{SZO}-\mathrm{Sn}_{0.05} / \mathrm{CH}_{3} \mathrm{NH}_{3}$ $\mathrm{PbI}_{3} /$ spiro-OMeTAD/Al. The homogeneity of each layer and the good contact between them pointed out that the charge separation and movement in the device will occur easily, which should enhance the overall efficiency of the assembled devices. Furthermore, XPS measurements were performed to investigate the composition of the deposited SZO on FTO and perovskite on SZO films, Fig. $4 a-c$ and S2a and b in the ESI. $\dagger$ The results show the narrow spectral peaks of $\mathrm{Pb} 4 \mathrm{f}$ and I $3 \mathrm{~d}$ for MAPI, ${ }^{35}$ Fig. S2a and $\mathrm{b}, \dagger$ as well as the $\mathrm{O} 1 \mathrm{~s}, \mathrm{Zn} 2 \mathrm{p}$, and Sn $3 \mathrm{~d}$ peaks for SZO, Fig. $4 \mathrm{a}-\mathrm{c} .^{30}$ These peaks confirm the existence of all expected components in the deposited materials. The $\mathrm{Zn} 2 \mathrm{p}_{3 / 2} 2 \mathrm{p}_{1 / 3}$ 
(a)

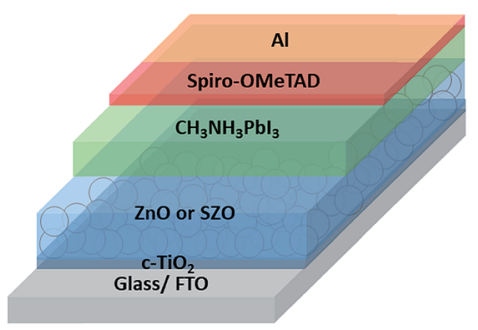

(b)

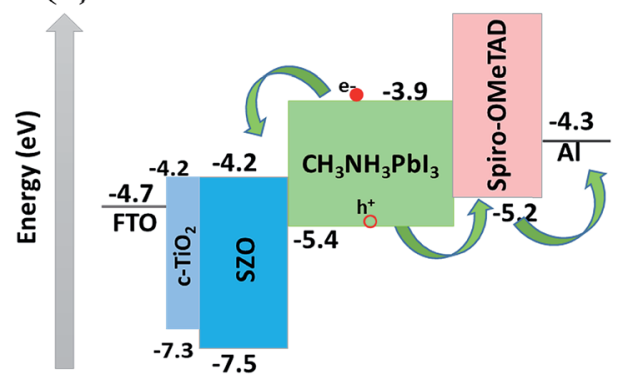

(c)

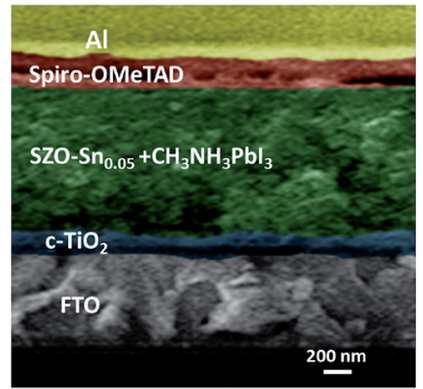

Fig. 3 (a) Schematic diagram, (b) energy level diagram, and (c) cross-sectional FESEM of the assembled solar cells with the configuration of FTO/ $\mathrm{C}-\mathrm{TiO}_{2} / \mathrm{SZO}-\mathrm{Sn}_{0.05} / \mathrm{CH}_{3} \mathrm{NH}_{3} \mathrm{Pbl}_{3} /$ spiro-OMeTAD/Al.

peaks either for $\mathrm{ZnO}$ or $\mathrm{SZO}-\mathrm{Sn}_{0.05}$, Fig. $4 \mathrm{a}$, at approximately 1029.6 and $1050.3 \mathrm{eV}$, respectively, are characteristic of $\mathrm{Zn}-\mathrm{O}$ bonds, ${ }^{30}$ which confirms the existence of $\mathrm{ZnO}$ composed with SnO nanoparticles by a facile solution processable wet chemical method. In addition, the XPS spectra of $\mathrm{Sn} 3 \mathrm{~d}$ for $\mathrm{SZO}-\mathrm{Sn}_{0.05}$ (Fig. $4 \mathrm{~b}$ ) indicated the presence of spin orbit components $3 \mathrm{~d}_{3 / 2}$ and $3 \mathrm{~d}_{5 / 2}$ at binding energies of 486.86 and $493.56 \mathrm{eV}$, respectively. ${ }^{30}$ Moreover, Fig. $4 \mathrm{c}$ shows the $\mathrm{O} 1 \mathrm{~s}$ spectra of $\mathrm{ZnO}$ and SZO- $\mathrm{Sn}_{0.05}$ samples. The incorporation of $\mathrm{Sn}^{2+}$ ions into the SZO structure can reinforce the contact barrier between the perovskite and SZO layers due to its unique chemical activity, ${ }^{35}$ which facilitates the electron transfer and thus enhances the efficiency of the fabricated devices.

Moreover, $\mathrm{N}_{2}$ sorption BET measurements were used to assess the mesoporous structure of the obtained nanocomposites via the huge number of small pores that exist between the nanoparticles, resulting in a higher surface area than that of pristine ZnO. The nitrogen sorption-desorption isotherm analysis of our materials shows specific surface areas $\left(S_{\mathrm{BET}}\right)$ of $34.04,49.12,61.37$, and $65.16 \mathrm{~m}^{2} \mathrm{~g}^{-1}$, pore volumes of $0.36,0.35,0.41$, and $0.39 \mathrm{~cm}^{3} \mathrm{~g}^{-1}$ and pore sizes of $42.3,29.3$, 26.8 , and $24.1 \mathrm{~nm}$ for pure $\mathrm{ZnO}, \mathrm{SZO}-\mathrm{Sn}_{0.05}, \mathrm{SZO}-\mathrm{Sn}_{0.1}$, and $\mathrm{SZO}-\mathrm{Sn}_{0.2}$, respectively. The obtained results indicate a direct proportion between the pore size, the pore volume, and the specific surface area.

Fourier-transform infrared (FTIR) spectroscopy was employed to further characterize the fabricated $\mathrm{SZO}-\mathrm{Sn}_{0.05}$ film as an example of SZO nanocomposite materials, Fig. S3, ESI. $\dagger$ While the peaks observed in the range 1000 and $1500 \mathrm{~cm}^{-1}$ can be ascribed to the vibration mode of Sn-O, the sharp and strong band appearing around $669 \mathrm{~cm}^{-1}$ is characteristic of the stretching mode of $\mathrm{Zn}-\mathrm{O}$. In addition, the presence of $-\mathrm{OH}$ (a)

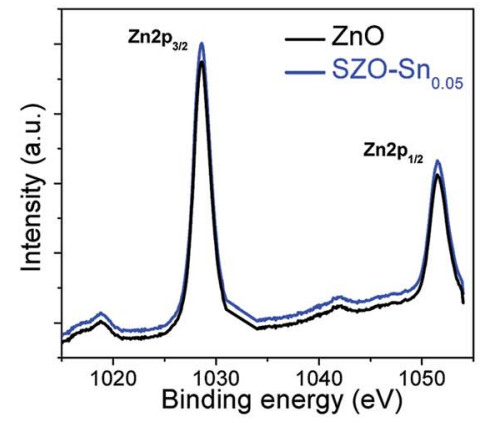

(b)

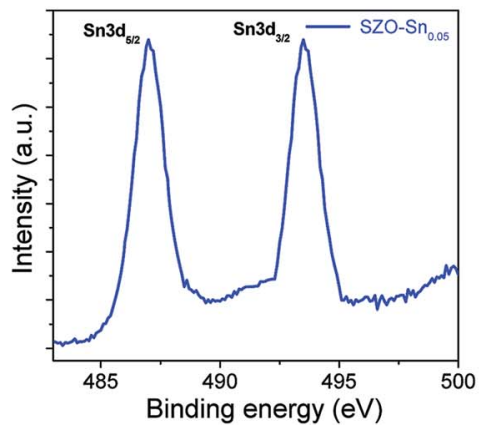

(c)

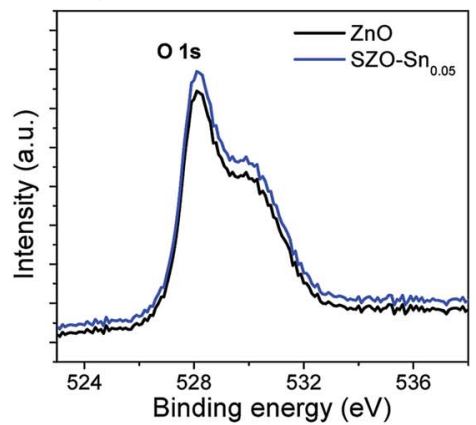

Fig. 4 Narrow-range X-ray photoelectron spectra (XPS) of (a) Zn $2 p_{3 / 2}$ and $Z n 2 p_{1 / 2}$ for ZnO and SZO-Sno.05 samples; (b) Sn $3 d_{5 / 2}$ and Sn $3 d_{3 / 2}$ for the $\mathrm{SZO}-\mathrm{Sn}_{0.05}$ sample; and (c) O $1 \mathrm{~s}$ for $\mathrm{ZnO}$ and $\mathrm{SZO}-\mathrm{Sn}_{0.05}$ samples. 
groups appears plainly via the obtained peaks corresponding to the stretching vibration of $\mathrm{O}-\mathrm{H}$ and bending vibrations of adsorbed water molecules at around $3300-3450 \mathrm{~cm}^{-1}$ and at $1640 \mathrm{~cm}^{-1}$, respectively. ${ }^{40}$ Furthermore, impurities like organic residues and contaminants, $-\mathrm{CH}$ and $-\mathrm{CH}_{2}$, are not observed in the obtained spectra, indicating the high purity of the synthesized materials.

The effect of Sn-substitution on the photovoltaic performance of the assembled devices is examined under simulated AM1.5 G illumination (100 $\mathrm{mW} \mathrm{cm}^{-2}$ ) as shown in (Fig. 5). The current-voltage $(J-V)$ and IPCE with integrated $J_{\text {sc }}$ measurements of the solar cells with $\mathrm{ZnO}$ or $\operatorname{SZO}(0.05,0.1$, and 0.2 molar ratio contents of $\mathrm{Sn}$, i.e. pure $\mathrm{ZnO}, \mathrm{SZO}-\mathrm{Sn}_{0.05}, \mathrm{SZO}-\mathrm{Sn}_{0.1}$, and $\mathrm{SZO}-\mathrm{Sn}_{0.2}$, respectively) as an ETL are compared to each other and the relevant photovoltaic parameters are summarized in Table 1. The SZO-based PVSCs showed better performance compared to that based on bare $\mathrm{ZnO}$. The power conversion efficiency (PCE) of all the tested devices was found to be increased with increasing the Sn content in the ETL. Note that the PCE was mainly dependent on the enhancement in $J_{\mathrm{sc}}$ upon the incorporation of Sn, which may be ascribed to (1) the positive shift in the Fermi level upon Sn incorporation, which improved the electron injection efficiency and reduced the interfacial resistance and (2) the larger surface area of SZO, resulting in better loading of the absorber materials with a better layer connection strength. ${ }^{30,37,38}$ Among all devices, the device containing the $\mathrm{SZO}-\mathrm{Sn}_{0.05}$ ETL exhibits the highest efficiency of 17.81 with a short circuit current density $\left(J_{\mathrm{sc}}\right)$ of 23.59 $\mathrm{mA} \mathrm{cm}{ }^{-2}$, an open-circuit voltage $V_{\mathrm{oc}}$ of $1 \mathrm{~V}$, and a fill factor (FF) of 0.754 . In addition, by measuring the forward scan to check the hysteresis behavior of our SZO solar cells, a small effect of hysteresis was noticed for these SZO devices, especially for SZO$\mathrm{Sn}_{0.05}$-based devices compared to the ZnO-based devices, Fig. S4, ESI. $\dagger$ The scan range with varied initial bias plays an important role in the hysteretic behavior and can alter the PV performance. ${ }^{35}$ The small difference in $J_{\mathrm{sc}}$ between the reverse and forward scans is one possible reason behind the low hysteresis effect observed, Fig. S4, ESI, $\dagger$ which originates from the low applied voltage to these cells. Upon increasing the $\mathrm{Sn}$ content to 10 and $20 \%$, i.e. $\mathrm{SZO}-\mathrm{Sn}_{0.1}$ and $\mathrm{SZO}-\mathrm{Sn}_{0.2}$,
Table 1 Photovoltaic parameters of $J_{\mathrm{sC}}, V_{\mathrm{OC}}, \mathrm{FF}$, and PCE of PVSCS based on $\mathrm{ZnO}, \mathrm{SZO}-\mathrm{Sn}_{0.05}, \mathrm{SZO}-\mathrm{Sn}_{0.1}$ and $\mathrm{SZO}-\mathrm{Sn}_{0.2}$ materials as ETLS

\begin{tabular}{llllll}
\hline Devices $^{a}$ & $J_{\mathrm{sc}} / \mathrm{mA} \mathrm{cm}^{-2}$ & $V_{\mathrm{oc}} / \mathrm{V}$ & $\mathrm{FF}$ & PCE$^{b}$ & $E_{\mathrm{g}}(\mathrm{eV})$ \\
\hline $\mathrm{ZnO}$ & 17.43 & 0.99 & 0.696 & $12.02(11.73 \pm 0.25)$ & 3.15 \\
$\mathrm{SZO}-\mathrm{Sn}_{0.05}$ & 23.59 & 1.00 & 0.754 & $17.81(17.21 \pm 0.42)$ & 3.05 \\
$\mathrm{SZO} \mathrm{Sn}_{0.1}$ & 22.18 & 1.00 & 0.715 & $15.86(15.44 \pm 0.36)$ & 3.10 \\
$\mathrm{SZO} \mathrm{Sn}_{0.2}$ & 20.78 & 0.98 & 0.677 & $13.80(13.20 \pm 0.36)$ & 3.10
\end{tabular}

${ }^{a}$ The devices were fabricated using $\mathrm{ZnO}, \mathrm{SZO}-\mathrm{Sn}_{0.05}, \mathrm{SZO}-\mathrm{Sn}_{0.1}$ and SZO-Sn $\mathrm{Sn}_{0.2}$ materials as electron transfer layers (ETLs). ${ }^{b}$ The average values shown in parentheses were obtained from 30 devices fabricated under the same experimental conditions for each ETL material.

respectively, the cell performance deteriorates, which can be attributed to the formation of a separate SnO phase that could act as a charge trapping site for electron-hole recombination..$^{30,37}$ On the other hand, the IPCE measurements also support the dramatic improvement in the photocurrent density (Fig. 5b). The incorporation of the SZO-Sn ${ }_{0.05}$ ETL in the device structure resulted in more than $90 \%$ improvement in the IPCE in the wavelength range of $400-800 \mathrm{~nm}$, whereas the photocurrent was dramatically reduced when the $\mathrm{Sn}$ content exceeds $5 \%$, i.e. $\mathrm{SZO}-\mathrm{Sn}_{0.1}$ and $\mathrm{SZO}-\mathrm{Sn}_{0.2}$. The reduction in photocurrent at a higher $\mathrm{Sn}$ content is mainly related to the reduction in the perovskite loading and inefficient electron injection from the perovskite to the ETL. ${ }^{39}$ Fig. $5 \mathrm{~b}$ shows an integrated $J_{\mathrm{sc}}$ of $16.17,21.94,20.56$, and $18.90 \mathrm{~mA} \mathrm{~cm}^{-2}$ for the devices made of bare $\mathrm{ZnO}, \mathrm{SZO}-\mathrm{Sn}_{0.05}, \mathrm{SZO}-\mathrm{Sn}_{0.1}$ and $\mathrm{SZO}-\mathrm{Sn}_{0.2}$ ETLs, respectively. These $J_{\mathrm{sc}}$ values are in agreement with the experimentally obtained $J_{\mathrm{sc}}$ for the assembled cells within the experimental uncertainties, which indicate the plausible method of fabrication.

To better understand the difference in the photovoltaic performance of the tested devices, absorption and steady-state photoluminescence (PL) measurements were performed as convenient tools to investigate the charge carrier trapping, migration and transfer. ${ }^{41}$ Fig. 6a demonstrates the PL and absorption spectra of the perovskite absorber layer (a)

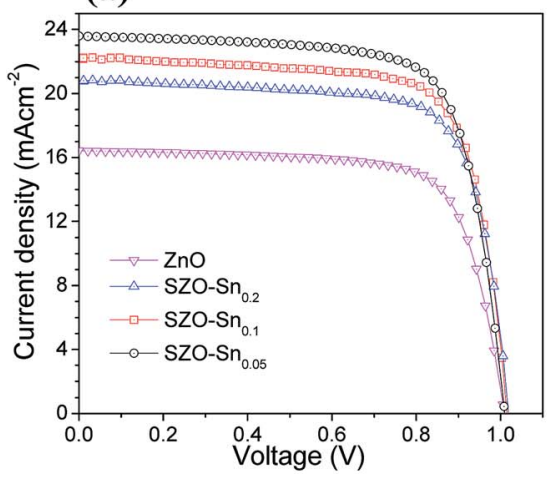

(b)

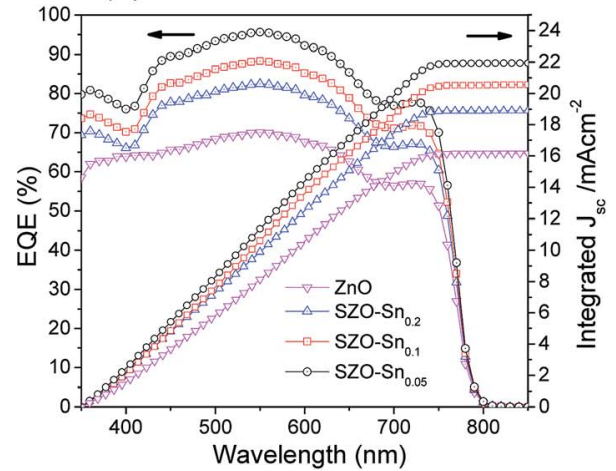

Fig. 5 (a) J-V curves, (b) EQE spectra and integrated current density of pristine $\mathrm{ZnO}, \mathrm{SZO}-\mathrm{Sn}_{0.05}, \mathrm{SZO}-\mathrm{Sn}_{0.1}$ and $\mathrm{SZO}-\mathrm{Sn}_{0.2}$, respectively, as effective ETLs for the best PVSCs. 

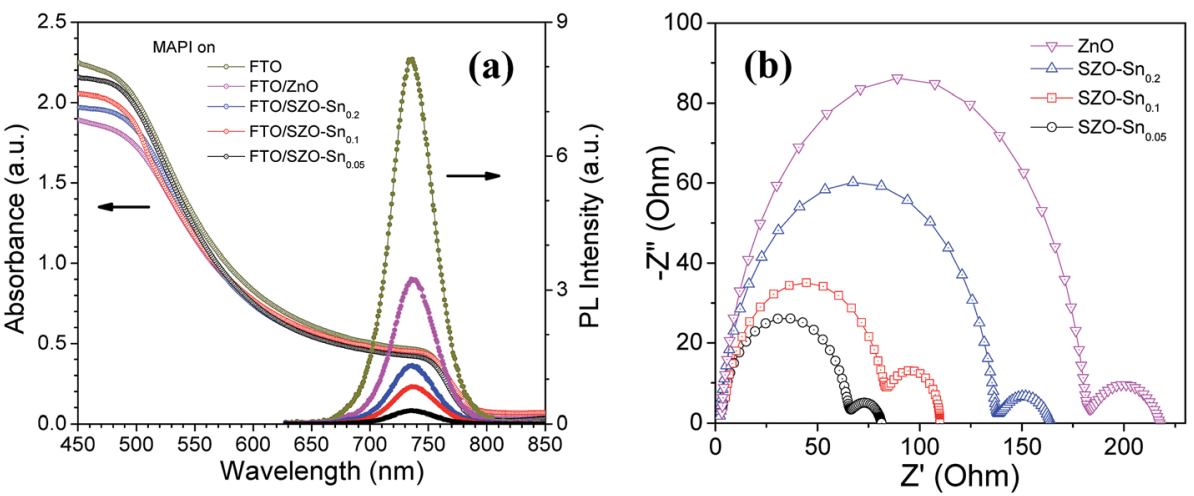

Fig. 6 (a) Absorption spectrum and steady-state photoluminescence spectrum (PL) of the perovskite (MAPI) on FTO, bare $\mathrm{ZnO}$ and $\mathrm{SZO}-\mathrm{Sn} \mathrm{n}_{0.05}$ $\mathrm{SZO}-\mathrm{Sn}_{0.1}$ and SZO-Sno.2 films, respectively; (b) Nyquist curve impedance spectra of the best PVSC devices based on pristine ZnO and SZO$\mathrm{Sn}_{0.05}, \mathrm{SZO}-\mathrm{Sn}_{0.1}$ and $\mathrm{SZO}-\mathrm{Sn}_{0.2}$ films, respectively.

$\left[\mathrm{CH}_{3} \mathrm{NH}_{3} \mathrm{PbI}_{3}\right.$, (MAPI)] deposited on the bare FTO glass, $\mathrm{ZnO}$ or SZO ETLs. The perovskite films with the SZO-Sn 0.05 ETL show the highest absorption values compared with the other films, probably due to the higher surface area of the SZO mesoporous structure that enables better light harvesting. Note that the emission peaks appearing at $\sim 740 \mathrm{~nm}$ originate from MAPI. The quenching in the PL intensity, compared to bare FTO, is due to the contact between $\mathrm{CH}_{3} \mathrm{NH}_{3} \mathrm{PbI}_{3}$ and the ETL layer, indicating good charge extraction across the interface. ${ }^{42}$ The more significant decrease in the intensity for SZO samples compared to the bare $\mathrm{ZnO}$ counterpart indicates more efficient electron transfer from the perovskite layer to SZO, proving that Sn substitution can successfully enhance the electron extraction rate at the ETL/MAPI interface. ${ }^{43,44}$ The results demonstrate that SZO- $\mathrm{Sn}_{0.05}$ exhibits the strongest PL quenching efficiency, the best injection ability, and the lowest recombination behavior, which would help to enhance the overall performance of the assembled perovskite solar cells. Furthermore, the results demonstrate that $\mathrm{SZO}_{-} \mathrm{Sn}_{0.05}$ exhibits the strongest $\mathrm{PL}$ quenching efficiency, the best injection ability, and the lowest recombination behavior, which would help to enhance the overall performance of the assembled perovskite solar cells. As the material absorbs more light, the number of photogenerated charge carriers increases. If those charge carriers are well separated with minimum recombination, the probability of PL quenching increases. This result, in conjunction with the SZO$\mathrm{Sn}_{0.05}$ sample having the highest absorption of the various devices, gives the best overall performance of the $\mathrm{SZO}-\mathrm{Sn}_{0.05}$ sample. In addition, the optical transmittance and the bandgap energy $\left(E_{\mathrm{g}}\right)$ of the different ETLs and MAPI can be evaluated from the Tauc plots shown in Fig. S5, ESI. $\dagger$ The band gap is redshifted from 3.15 to $3.05 \mathrm{eV}$ for $\mathrm{ZnO}$ and different SZO films as illustrated in Table 1 . This decrease in the band gap results in an enhancement in the photoconversion efficiency of the SZO films due to the easy movement of electrons and holes between materials in the device structure. ${ }^{45,46}$

To further assess the charge separation and charge recombination in the prepared ETL materials, electrochemical impedance spectroscopy (EIS) measurements were performed as shown in Fig. 6b. The obtained results show two semicircles, one in the high frequency range representing the carriertransport resistance $\left(R_{1}\right)$ at the interface between the perovskite layer and the ETL when the same hole transport material (spiroOMeTAD) was used, and the other one is related to the charge recombination resistance $\left(R_{2}\right)$ at the SZO/MAPI interface. ${ }^{47,48}$ While $R_{1}$ is lowest for the device made using the $\mathrm{SZO}-\mathrm{Sn}_{0.05}$ composite film, the device with a high content of $\mathrm{Sn}\left(\mathrm{SZO}-\mathrm{Sn}_{0.2}\right)$ exhibits a larger $R_{1}$, because a high content of Sn deteriorates the conductivity of the $\mathrm{ZnO}$ film as shown in Fig. 6b. Upon increasing the concentration of $\mathrm{Sn}$, the recombination resistance increases gradually and the device with the $\mathrm{SZO}-\mathrm{Sn}_{0.05}$ composite film has the smallest $R_{2}$, which probably occurs because the low concentration of $\mathrm{Sn}$ impurities reduces the recombination of the charge carriers.

Note that the obtained PCE results (Table 1) are in good correlation with the roughness of the ETLs. Moreover, previous studies claimed that if the conductivity of the ETL increases, the net efficiency of the assembled devices would increase. ${ }^{49}$ Therefore, to emphasize the relationship between roughness and conductivity and their impact on the device performances, the resistivity of $\mathrm{ZnO}$ and SZO was measured using an electrochemical analyzer (Potentiostat Model Parastat Princeton 4000). The resistivities of $\mathrm{ZnO}, \mathrm{SZO}-\mathrm{Sn}_{0.05}, \mathrm{SZO}-\mathrm{Sn}_{0.1}$ and $\mathrm{SZO}-\mathrm{Sn}_{0.2}$ were found to be $90,24,37$, and $62 \Omega \mathrm{cm}^{-1}$, corresponding to conductivities of 11.11, 41.66, 27.02, and $16.12 \mathrm{mS} \mathrm{m}^{-1}$, respectively. In addition, Fig. S6, ESI $\dagger$ illustrates the correlation between the PCE and the roughness of the different ETLs and their conductivity. Note the good interconnection between the roughness and conductivity of the different ETLs and the obtained PCEs of the assembled cells, where increasing the roughness and conductivity of the ETL resulted in the increase of the net PCE of the devices.

Fig. $7 \mathrm{a}$ and S7a-c, ESI $\dagger$ show the average photovoltaic parameter distribution histogram diagrams of 30 devices, demonstrating very good reproducibility with limited variation. The obtained average PCEs with the corresponding standard deviation are $11.73 \pm 0.25,17.21 \pm 0.42,15.44 \pm 0.36$, and 13.20 $\pm 0.36 \%$ for the devices using bare $\mathrm{ZnO}$, $\mathrm{SZO}-\mathrm{Sn}_{0.05}, \mathrm{SZO}^{-\mathrm{Sn}_{0.1}}$ 

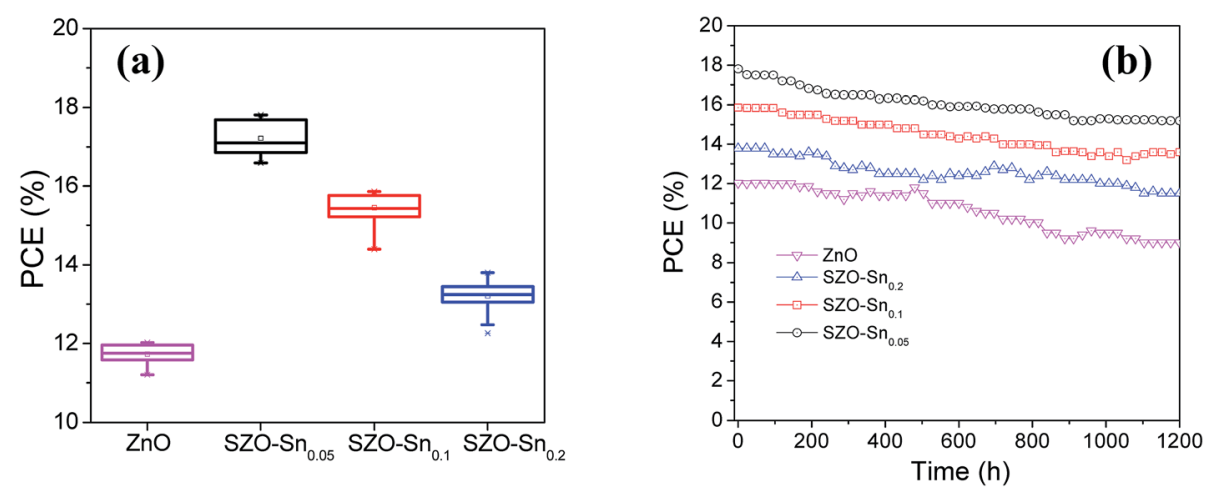

Fig. 7 (a) Box chart of PCEs for the 30 solar cell devices and (b) efficiency of encapsulated devices as a function of the storage time.

and $\mathrm{SZO}-\mathrm{Sn}_{0.2}$ as ETLs, respectively. The corresponding average $J_{\mathrm{sc}}$ values are $17.19 \pm 0.53,22.85 \pm 0.75,21.51 \pm 0.68$, and 19.95 $\pm 0.36 \mathrm{mAcm}^{-2}$ (Fig. S7a, ESI $\dagger$ ), and average $V_{\mathrm{oc}}$ values of $0.98 \pm$ $0.014,0.99 \pm 0.003,1.00 \pm 0.001$, and $0.98 \pm 0.013 \mathrm{~V}$ (Fig. S7b, ESI $\dagger$ ) and average FF of $69.21 \pm 3.03,75.40 \pm 2.08,71.83 \pm 1.56$, and $67.09 \pm 1.63$ (Fig. S7c, ESI $\dagger$ ) as listed in detail in Tables S2S5, ESI. $\uparrow$ The highest PCE was found for the device using SZO$\mathrm{Sn}_{0.05}$ as an ETL, mainly due to the highest $J_{\mathrm{sc}}$, which is because of the most efficient interfacial charge transfer and the lowest carrier recombination as confirmed from the EIS measurements (Fig. 6b). ${ }^{31,50}$ Fig. 7b shows the stability of the assembled solar cell devices made using bare ZnO or SZO ETLs during storage in ambient air environment at room temperature over $\sim 1200 \mathrm{~h}$. Although the four devices showed almost similar stability in the first $600 \mathrm{~h}$, increasing the storage time reduces the PCE of bare ZnO-devices more significantly than the SZOdevice counterparts, where the efficiency decreased from 12.02 to $9 \%$, accounting for $30 \%$ loss. However, the SZO-devices with $5 \%$ Sn retained $\sim 85 \%$ of their initial efficiency of $17.81 \%$ under the same conditions. Therefore, it is clear that the introduction of Sn into $\mathrm{ZnO}$, which can act as a shield to prevent the dissolution of the perovskite layer, results in the best stability of PVSCs compared to other materials studied elsewhere. ${ }^{31}$

\section{Conclusion}

We demonstrated the positive effect of Sn substitution into the ZnO structure for use as an efficient ETL for PVSCs. The fabricated cells using ETLs containing 5, 10 and 20\% Sn, i.e. SZO$\mathrm{Sn}_{0.05}, \mathrm{SZO}-\mathrm{Sn}_{0.1}$, and $\mathrm{SZO}-\mathrm{Sn}_{0.2}$, respectively, showed a relatively high photovoltaic performance with a maximum PCE of $17.81 \%$ compared to $12.02 \%$ for the PVSC based on bare $\mathrm{ZnO}$ as the ETL. Quenching of the photoluminescence in the Sn-containing devices suggested efficient extraction of the charge carriers with the suppression of the electron-hole recombination at the $\mathrm{SZO} / \mathrm{CH}_{3} \mathrm{NH}_{3} \mathrm{PbI}_{3}$ interface. The obtained high PCE was further asserted via electrochemical impedance spectroscopy measurements, which indicated low recombination resistance in the devices. More importantly, 30 devices were thoroughly tested to investigate the reproducibility of the devices' performance, indicating that the $\mathrm{SZO}-\mathrm{Sn}_{0.05}$ films exhibited the best durability as compared to bare ZnO. Finally, the presence of $\mathrm{Sn}$ in the $\mathrm{ZnO}$ lattice enhanced not only the photovoltaic performance but also the photo-stability of PVSCs as revealed by the long-term stability tests for $1200 \mathrm{~h}$.

\section{Funding}

This work was funded by the Science \& Technology Development Fund in Egypt (STDF), grants no. 33338 and 25250.

\section{Conflicts of interest}

There is no competing financial interest declared.

\section{Acknowledgements}

The Science \& Technology Development Fund in Egypt (STDF), Central Metallurgical Research and Development Institute (CMRDI), and American University in Cairo (AUC), Cairo, Egypt are highly appreciated by the authors for their support to pursue this work.

\section{References}

1 W. S. Yang, B. W. Park, E. H. Jung, N. J. Jeon, Y. C. Kim, D. U. Lee, S. S. Shin, J. Seo, E. K. Kim, J. H. Noh and S. I. Seok, Science, 2017, 356, 1376-1379.

2 T. B. Song, Q. Chen, H. Zhou, C. Jiang, H. H. Wang, Y. M. Yang and Y. Yang, J. Mater. Chem. A, 2015, 3, 90329050.

3 Q. Fu, X. Tang, B. Huang, T. Hu, L. Tan, L. Chen and Y. Chen, Adv. Sci., 2018, 5, 1700387.

4 M. A. Mahmud, N. K. Elumalai, M. B. Upama, D. Wang, K. H. Chan, M. Wright and A. Uddin, Sol. Energy Mater. Sol. Cells, 2017, 159, 251-264.

5 E. J. Juarez-Perez, M. Wußler, F. Fabregat-Santiago, K. LakusWollny, E. Mankel, T. Mayer and I. Mora-Sero, J. Phys. Chem. Lett., 2014, 5, 680-685.

6 A. E. Shalan, M. M. Rashad, Y. Yu, M. Lira-Cantú and M. S. A. Abdel-Mottaleb, Electrochim. Acta, 2013, 89, 469-478. 
7 L. Yuan, Z. Wang, R. Duan, P. Huang, K. Zhang, Q. Chen, S. Min, N. K. Allam, Y. Zhou, B. Song and Y. Li, J. Mater. Chem. A, 2018, 6, 19696-19702.

8 O. A. M. Abdelraouf, A. Shaker and N. K. Allam, Opt. Mater., 2018, 86, 311-317.

9 X. Ling, J. Yuan, D. Liu, Y. Wang, Y. Zhang, S. Chen and X. Tang, ACS Appl. Mater. Interfaces, 2017, 9, 23181-23188.

10 K. Mahmood, B. S. Swain, A. R. Kirmani and A. Amassian, J. Mater. Chem. A, 2015, 3, 9051-9057.

11 E. C. Muniz, M. S. Goes, J. J. Silva, J. A. Varela, E. Joanni, R. Parra and P. R. Bueno, Ceram. Int., 2011, 37, 1017-1024.

12 A. E. Shalan and M. M. Rashad, Appl. Surf. Sci., 2013, 283, 975-981.

13 K. Sivakumar, V. S. Kumar, N. Muthukumarasamy, M. Thambidurai and T. S. Senthil, Bull. Mater. Sci., 2012, 35, 327-331.

14 F. M. Li, G. W. Hsieh, S. Dalal, M. C. Newton, J. E. Stott, P. Hiralal, A. Nathan, P. A. Warburton, H. E. Unalan, P. Beecher, A. J. Flewitt, I. Robinson, G. Amaratunga and W. I. Milne, IEEE Trans. Electron Devices, 2008, 55, 30013011.

15 Y. Guo, X. Li, L. L. Kang, X. He, Z. Q. Ren, J. D. Wu and J. Y. Qi, RSC Adv., 2016, 6, 62522-62528.

16 Y. Cheng, Q. D. Yang, J. Xiao, Q. Xue, H. W. Li, Z. Guan, H. L. Yip and S. W. Tsang, ACS Appl. Mater. Interfaces, 2015, 7, 19986-19993.

17 O. A. M. Abdelraouf, A. Shaker and N. K. Allam, Sol. Energy, 2018, 174, 803-814.

18 G. S. Han, H. W. Shim, S. Lee, M. L. Duff and J. K. Lee, ChemSusChem, 2017, 10, 2425-2430.

19 J. Song, E. Zheng, J. Bian, X. F. Wang, W. Tian, Y. Sanehira and T. Miyasaka, J. Mater. Chem. A, 2015, 3, 10837-10844.

20 Q. Wen, J. Zhuang, Q. He, Y. Deng, H. Li and J. Guo, RSC Adv., 2015, 5, 91997-92003.

21 Z. Zhang, C. Shao, X. Li, L. Zhang, H. Xue, C. Wang and Y. Liu, J. Phys. Chem. C, 2010, 114, 7920-7925.

22 M. T. Uddin, Y. Nicolas, C. Olivier, T. Toupance, L. Servant, M. M. Müller and W. Jaegermann, Inorg. Chem., 2012, 51, 7764-7773.

23 M. M. Rashad, A. A. Ismail, I. Osama, I. A. Ibrahim and A. H. T. Kandil, Arabian J. Chem., 2014, 7, 71-77.

24 B. N. Joshi, S. An, H. S. Jo, K. Y. Song, H. G. Park, S. Hwang, S. S. Al-Deyab, W. Y. Yoon and S. S. Yoon, ACS Appl. Mater. Interfaces, 2016, 8, 9446-9453.

25 N. Feng, L. Qiao, D. Hu, X. Sun, P. Wang and D. He, RSC Adv., 2013, 3, 7758-7764.

26 R. Milan, G. S. Selopal, M. Epifani, M. M. Natile, G. Sberveglieri, A. Vomiero and I. Concina, Sci. Rep., 2015, 5, 14523.

27 L. Zhu, M. Hong and G. W. Ho, Sci. Rep., 2015, 5, 11609.

28 S. Sujinnapram and S. Moungsrijun, Procedia Manufacturing, 2015, 2, 108-112.

29 A. E. Shalan, M. Rasly, I. Osama, M. M. Rashad and I. A. Ibrahim, Ceram. Int., 2014, 40, 11619-11626.
30 A. N. El-Shazly, A. E. Shalan, M. M. Rashad, E. A. Abdel-Aal, I. A. Ibrahim and M. F. El-Shahat, RSC Adv., 2018, 8, 2405924067.

31 J. Song, E. Zheng, X. F. Wang, W. Tian and T. Miyasaka, Sol. Energy Mater. Sol. Cells, 2016, 144, 623-630.

32 K. C. Wang, J. Y. Jeng, P. S. Shen, Y. C. Chang, E. W. Diau, C. H. Tsai, T. Y. Chao, H. C. Hsu, P. Y. Lin, P. Chen, T. F. Guo and T. C. Wen, Sci. Rep., 2014, 4, 4756.

33 C.-Y. Chan, Y. Wang, G.-W. Wu and E. W.-G. Diau, J. Mater. Chem. A, 2016, 4, 3872-3878.

34 A. E. Shalan, T. Oshikiri, S. Narra, M. M Elshanawany, K. Ueno, H.-P. Wu, K. Nakamura, X. Shi, E. W.-G. Diau and H. Misawa, ACS Appl. Mater. Interfaces, 2016, 8, 33592-33600.

35 A. E. Shalan, S. Narra, T. Oshikiri, K. Ueno, X. Shi, H.-P. Wu, M. M. Elshanawany, E. W.-G. Diau and H. Misawa, Sustainable Energy Fuels, 2017, 1, 1533-1540.

36 A. E. Shalan, T. Oshikiri, H. Sawayanagi, K. Nakamura, K. Ueno, Q. Sun, H.-P. Wu, E. W.-G. Diau and H. Misawa, Nanoscale, 2017, 9, 1229-1236.

37 H. Yea, Z. Liu, X. Liu, B. Sun, X. Tan, Y. Tu, T. Shi, Z. Tanga and G. Liao, Appl. Surf. Sci., 2019, 478, 417-425.

38 M. I. Ahmed, Z. Hussain, M. Mujahid, A. N. Khan, S. S. Javaid and A. Habib, AIP Adv., 2016, 6, 065303.

39 D. T. Gangadharan, Z. Xu, Y. Liu, R. Izquierdo and D. Ma, Nanophotonics, 2016, 6, 153-175.

40 A. M. Elseman, A. E. Shalan, M. M. Rashad and A. M. Hassan, Mater. Sci. Semicond. Process., 2017, 66, 176-185.

41 Z.-L. Zhang, J.-F. Li, X.-L. Wang, J.-Q. Qin, W.-J. Shi, Y.-F. Liu, H.-P. Gao and Y.-L. Mao, Nanoscale Res. Lett., 2017, 12, 43.

42 P.-Y. Chen and S.-H. Yang, Opt. Mater. Express, 2016, 6, 36513669.

43 Q. Cai, Y. Zhang, C. Liang, P. Li, H. Gu, X. Liu, J. Wang, Z. Shentu, J. Fan and G. Shao, Electrochim. Acta, 2018, 261, 227-235.

44 R. Zhang, C. Fei, B. Li, H. Fu, J. Tian and G. Cao, ACS Appl. Mater. Interfaces, 2017, 9, 9785-9794.

45 I. Ali, Z. Ullah, K. Siraj, M. S. Rafique and M. Khaleeq-urRahman, Int. J. Thin Films Sci. Tech., 2014, 3, 107.

46 A. D. Acharya, S. Moghe, R. Panda, S. B. Shrivastava, M. Gangrade, T. Shripathi, D. M. Phase and V. Ganesan, J. Mol. Struct., 2012, 1022, 8-15.

47 S. Ma, J. Ahn, Y. Oh, H.-C. Kwon, E. Lee, K. Kim, S.-C. Yun and J. Moon, ACS Appl. Mater. Interfaces, 2018, 10, 1464914658.

48 S. Li, J. Hu, Y. Yang, L. Zhao, Y. Qiao, W. Liu, P. Liu and M. Chen, Appl. Phys. A: Mater. Sci. Process., 2017, 123, 628.

49 A. E. Shalan, A. M. Elseman, M. Rasly, M. M. Moharam, M. L. Cantu and M. M. Rashad, RSC Adv., 2015, 5, 103095103104.

50 W. Ke, G. Fang, Q. Liu, L. Xiong, P. Qin, H. Tao, J. Wang, H. Lei, B. Li, J. Wan, G. Yang and Y. Yan, J. Am. Chem. Soc., 2015, 137, 6730-6733. 